\title{
2,7-Dichlorofluorescein Hydrazide as a New Fluorescent Probe for Mercury Quantification: Application to Industrial Effluents and Polluted Water Samples
}

\author{
Sureshkumar Kempahanumakkagari, ${ }^{1}$ Pandurangappa Malingappa, \\ Gopi Ambikapathi, ${ }^{2}$ and Devaraju Kuramkote Shivanna ${ }^{2}$ \\ ${ }^{1}$ Department of Studies in Chemistry, Bangalore University, Central College Campus, Bangalore 560 001, India \\ ${ }^{2}$ Department of Microbiology \& Biotechnology, Bangalore University, Jnanabharathi Campus, Bangalore 560 056, India
}

Correspondence should be addressed to Pandurangappa Malingappa; mprangachem@gmail.com

Received 19 June 2012; Accepted 19 September 2012

Academic Editor: Nives Galić

Copyright (C) 2013 Sureshkumar Kempahanumakkagari et al. This is an open access article distributed under the Creative Commons Attribution License, which permits unrestricted use, distribution, and reproduction in any medium, provided the original work is properly cited.

\begin{abstract}
A new fluorescent probe 2,7-dichlorofluorescein hydrazide for mercury quantification in aqueous medium has been described. It is based on the spirolactam ring opening of colorless and nonfluorescent 2,7-dichlorofluorescein hydrazide induced by $\mathrm{Hg}^{2+}$ ions through the hydrolytic cleavage of amide bond to produce green-colored highly fluorescent dichlorofluorescein in alkaline medium. The significant color change of this reagent in the presence of mercury ions can be used as a sensitive naked-eye detector. The working range, limit of detection, and relative standard deviations were found to be $0.2-20 \mathrm{ngmL}^{-1}, 0.042 \mathrm{ngmL}^{-1}$, and $0.69 \%$ respectively. The proposed method is free from most of the common interfering ions present in the environmental samples. The developed method has been successfully applied to determine trace level mercury from water, soil, and industrial effluents.
\end{abstract}

\section{Introduction}

Global mercury emissions have increased substantially in recent years due to increased human activity mainly through the emissions from coal burning power plants, gold mining operations, and industrial processes [1]. Mercury is a volatile element and has a long atmospheric residence time which results in long-range transport and homogenization on a hemispherical scale. Toxic effects of mercury include damage to DNA, kidney, digestive, and neurological systems, impairing the mitosis, and disturbing the central nervous as well as endocrine systems [2]. Other health effects caused by mercury are due to its high affinity towards thiol groups of the proteins and enzymes leading to the dysfunction of cells and consequently causing health problems [3]. Due to its serious toxic effects and increased concentrations in the environment, the Environmental Protection Agency of USA (USEPA) has set $2 \mathrm{ppb}$ as the maximum threshold limit value (TLV) for inorganic mercury in drinking water [2]. Mercury contamination in the environment is of widespread and arises from a variety of natural sources [4]. Every year nearly 2700-6000 tones of elemental mercury is released into the atmosphere by volcanic eruption and about 2000-3000 tones by the coal combustion, gold production, and other industrial processes [5]. Its wide utility in industrial processes like catalysis, amalgams, electrodes, lamps, batteries, thermometers, fungicides, pigments, and so forth is due to its characteristic physicochemical properties [6]. Another important source of mercury is chloralkali industry where the electrolytic bath consists of mercury as a cathode during the electrolysis of $\mathrm{NaCl}$ [7]. The above-mentioned industrial sources release their effluents into the nearby water bodies. The various species of fish and bacteria in aqueous environments have the ability to transform the elemental mercury into organo mercuric species like methyl, ethyl, and phenyl mercury species which are most toxic to living systems and also a neurotoxin [8]. It exists mainly in three forms in the environment, that is, ionic, organics and elemental form. Depending on the 


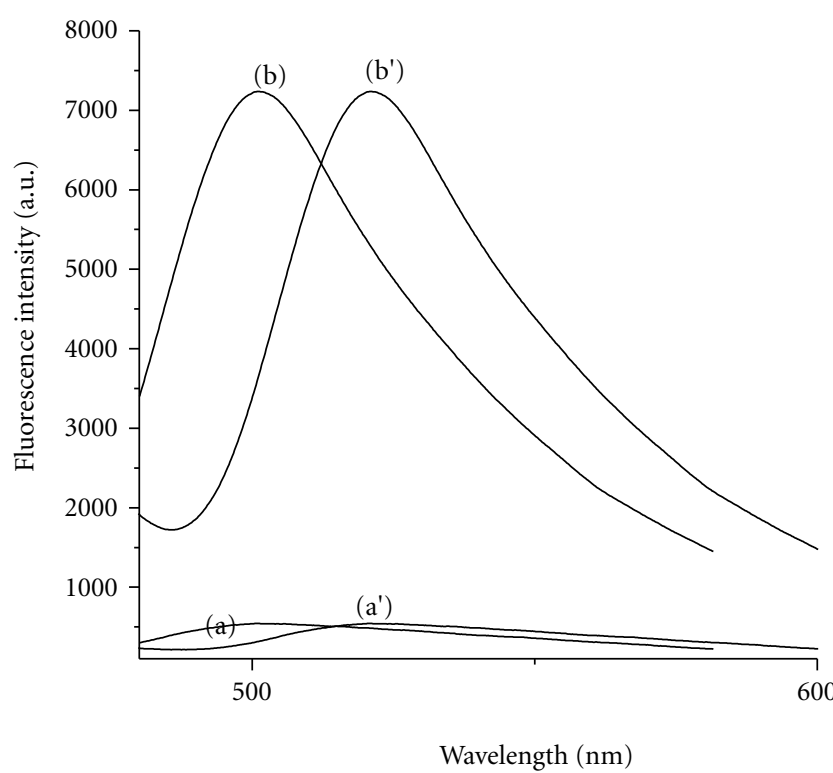

FIGURE 1: Excitation and emission spectrum of ((a), $\left.\left(a^{\prime}\right)\right)$ 2,7dichlorofluorescein hydrazide $(10 \mathrm{mM})$ in the absence of mercury and ((b), $\left(b^{\prime}\right)$ ) 2,7-dichlorofluorescein hydrazide $(10 \mathrm{mM})$ in the presence of $\mathrm{Hg}^{2+}$ ions $\left(100 \mathrm{ngmL}^{-1}\right)$.

environmental conditions, it can transform into different forms; hence, the existence of mercury in any form in the environmental matrices is potentially harmful to human health. In order to control the mercury toxicity, it is very much essential to know the concentrations of different species of mercury present in various environmental samples mainly in industrial effluents which were disposed into water bodies without proper treatment. Over the years, a great emphasis has been given on the development of sensing sensors for mercury monitoring involving chemosensors, fluorogenic chemosensors, and electrochemical devices [916]. Among all these, fluorogenic/chromogenic sensors are especially promising due to their simple naked-eye detectable application requiring less labour and inexpensive equipment when compared to electrochemical sensors. Several sensors have been reported for mercury determination from a variety of sample matrices [17-21]. However, most of these sensors are not suitable for practical use due to several limitations like poor selectivity, sensitivity, interference from other metal ions, delayed response to target ions, or water insoluble sensing probes which cannot be used under aqueous condition. Hence, there is a scope to develop inexpensive, realtime monitoring protocols for mercury determination at ultratrace level using fluorogenic/chromogenic molecules.

The metal ions can cleave and promote the hydrolytic cleavage of specific bonds like ester or amide bonds which are present in molecules like xanthenes and its derivatives accompanied by the change of spectroscopic properties of these molecules [22]. In recent years, several molecules have been explored as fluorogenic chemosensors for the quantification of metal ions at trace level [23]. Among them, rhodamine-based molecular probes are popular which have been extensively used as fluorogenic chemosensors for metal ions due to their selective spectroscopic properties [23]. It is well known that these xanthene derivatives are colorless and nonfluorescent in their closed spirolactam ring form, but they become highly fluorescent and colored in the presence of metal ions or $\mathrm{H}^{+}$ions due to the spirolactam ring opening process. This attractive switch, on or off the spectroscopic property of these molecules, has been utilized extensively for molecular sensing in recent years [24]. Dujlos et al. have reported a copper sensor based on rhodamine B hydrazide molecule [25]. Kim et al. and Pandurangappa as well as Kumar have showed that the same reagent can be tuned to determine mercury at trace level $[12,26]$. In these methods, copper/mercury ions promote the spirolactam ring opening of rhodamine $\mathrm{B}$ hydrazide by the reductive hydrolysis of amide bond of the molecule to produce rhodamine $B$. In the present paper, we have investigated the reaction between the mercury and a fluorescein derivative, that is, 2,7-dichlorofluorescein hydrazide which is in lactone form. Upon the addition of mercury to the colorless nonfluorescent lactone form of 2,7-dichlorofluorescein hydrazide, it immediately turns into green-colored and highly fluorescent 2,7dichlorofluorescein in stoichiometric quantities. This simple reaction has been explored as a new protocol for mercury quantification at trace level. The developed sensor has been successfully applied to various environmental samples. This reaction scheme can be used as a naked eye sensor at very low concentration level. This kind of sensor can be used in industrial locations as a preliminary warning signal in case of any alarming situation of high mercury level discharges into effluents due to any industrial hazards.

\section{Experimental}

2.1. Apparatus. Fluorescence measurements were recorded using Ocean Optics Spectrofluorimeter (model USB 4000). Absorbance measurements were made using a Shimadzu Scanning Spectrophotometer (model UV-3101PC) with $1 \mathrm{~cm}$ quartz cuvettes. All pH measurements were carried out using Control Dynamics digital pH meter (model APX 175). All the infrared measurements were performed using Shimadzu Spectrometer (model FTIR-8400S). Mass spectral data was obtained using Thermo Finnigan Deca QXP Mass Spectrometer. Elemental analysis was carried out using Elementar (model Vario super user).

2.2. Reagents and Solutions. 2,7-dichlorofluorescein hydrazide was prepared according to the literature reported (Scheme 1) [27]. It was characterized by TLC and elemental analysis. $R_{f}=0.57$ (silica, $\mathrm{CH}_{2} \mathrm{Cl}_{2} /$ methanol = 10/1, v/v); Anal. Calcd. for $\mathrm{C}_{20} \mathrm{~N}_{2} \mathrm{Cl}_{2} \mathrm{O}_{4} \mathrm{H}_{12}$ : C-57.863; N-6.745; H-2.89. Found C-57.869; N-6.338; H-2.99. 10 mM 2,7-dichlorofluorescein hydrazide was prepared by dissolving $0.0436 \mathrm{~g}$ of the reagent in $1: 10$ acetonitrile-water $(\%, \mathrm{~V} / \mathrm{V})$. Standard $\mathrm{Hg}^{2+}$ solution of $100 \mathrm{ppm}$ was prepared by dissolving $0.0179 \mathrm{~g}$ of $\mathrm{HgBr}_{2}$ (Merck, AR grade, Mumbai, INDIA.) in double-distilled water, and working solutions were prepared by diluting the appropriate volumes of the standard stock solution. Robinson buffer solutions of $\mathrm{pH}$ 7-12 were prepared by using a 


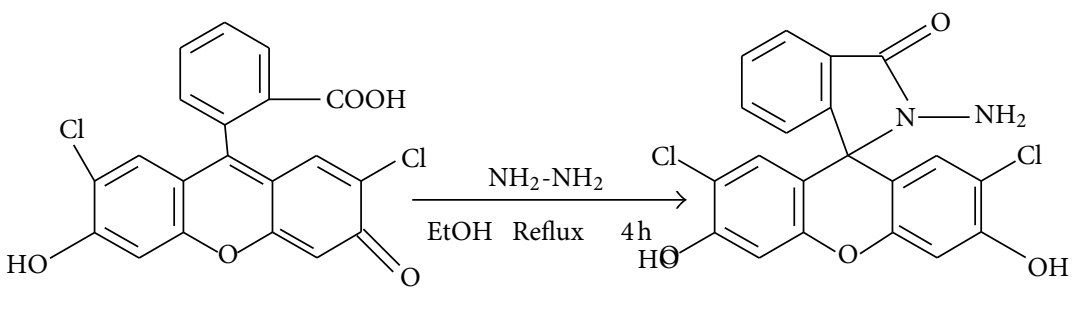

2,7-Dichlorofluorescein

2,7-Dichlorofluorescein hydrazide

SCHEME 1: Synthesis of 2,7-dichlorofluorescein hydrazide.

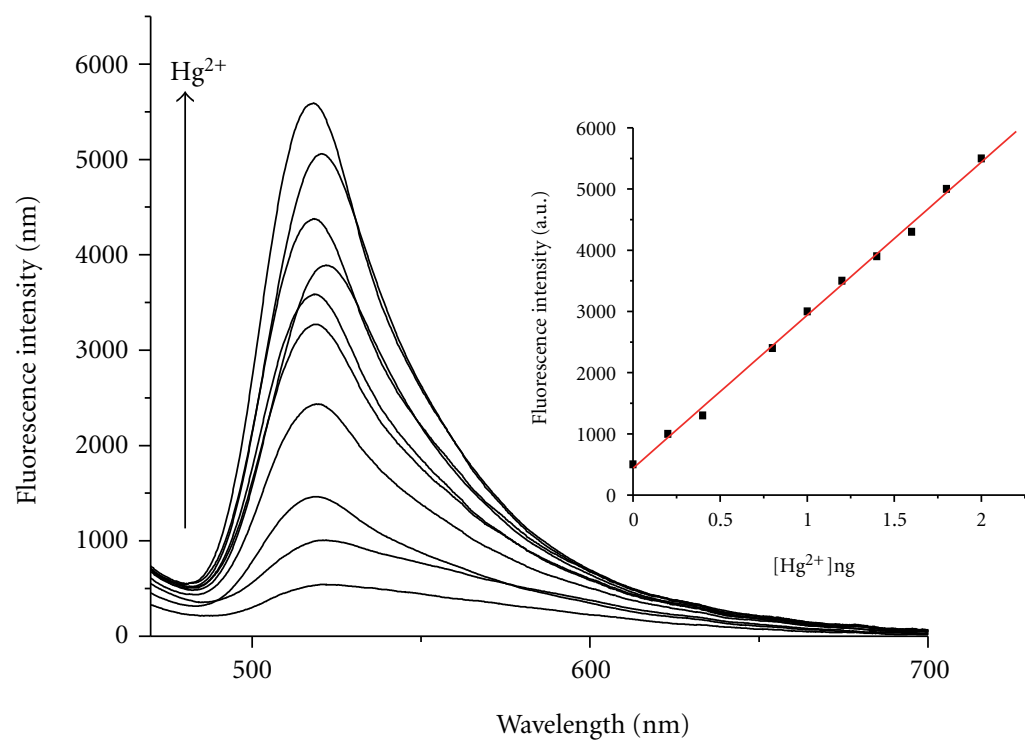

FIGURE 2: Fluorescence spectra of 2,7-dichlorofluorescien hydrazide in presence of variable mercury (II) concentrations $(\lambda$ ex/em $=502 / 520)$ (Inset: calibration plot, concentration 0.1-2.0 ngmL ${ }^{-1}$ ).

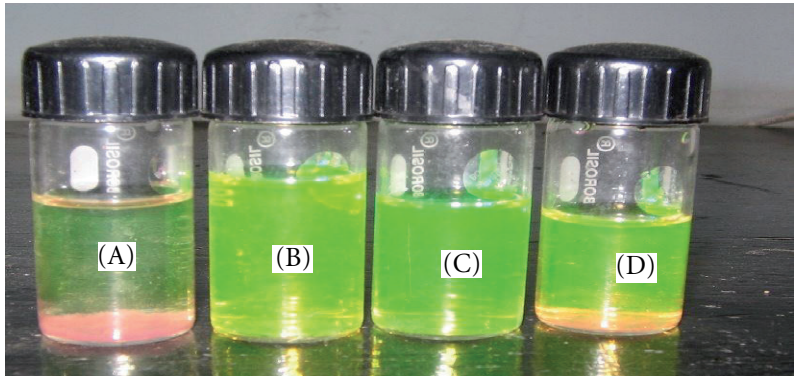

Figure 3: Naked eye sensor (A), reagent only (B), reagent $+\mathrm{Hg}^{2+}$ $(0.5 \mathrm{ppm})(\mathrm{C})$, reagent $+\mathrm{Hg}^{2+}(1.0 \mathrm{ppm})(\mathrm{D})$, and reagent + other interfering ions $(500 \mathrm{ppm})$.

mixture of solution containing $0.02 \mathrm{M}$ acetic acid, $0.02 \mathrm{M}$ orthophosphoric acid, $0.02 \mathrm{M}$ sodium tetra borate, and $0.4 \mathrm{M}$ $\mathrm{NaOH}$. Industrial waste water samples (chrome plating and textile dyeing industries) were obtained from Karnataka State Pollution Control Board, Bangalore, India. The soil sludge and water samples were collected from polluted lakes present in the vicinity of Bangalore city where painted clay idols of god/goddess of Hindu religion were dumped after the procession during festival season. The soil samples were collected from the agricultural fields and water samples from the polluted lakes as well as bore wells.

2.3. Recommended Procedure. Aliquots of solutions containing mercury (concentration range of $0.2-20 \mathrm{ngmL}^{-1}$ ) were taken into a series of $10 \mathrm{~mL}$ volumetric flasks. Then $2 \mathrm{~mL}$ of $10 \mathrm{mM}$ 2,7-dichlorofluorescein hydrazide solution was added followed by $1 \mathrm{~mL}$ of buffer solution of $\mathrm{pH} 12$. These solutions were allowed for $2 \mathrm{~min}$ and diluted up to the mark with distilled water. The green-colored species were excited at $502 \mathrm{~nm}$, and the emitted fluorescence intensities were recorded at $520 \mathrm{~nm}$.

\subsection{Sample Pretreatment}

2.4.1. Industrial Effluents. Industrial effluents from the chrome plating and textile industry were collected in polyethylene containers. The solutions were filtered, and $50 \mathrm{~mL}$ of filtered solution was transferred into a beaker, $10 \mathrm{~mL}$ each of con. sulphuric acid and $30 \% \mathrm{H}_{2} \mathrm{O}_{2}$ were added, and 


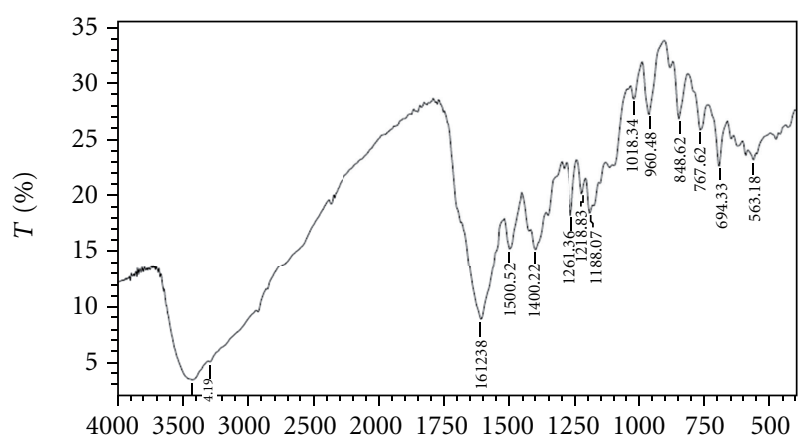

$(1 / \mathrm{cm})$

(a)

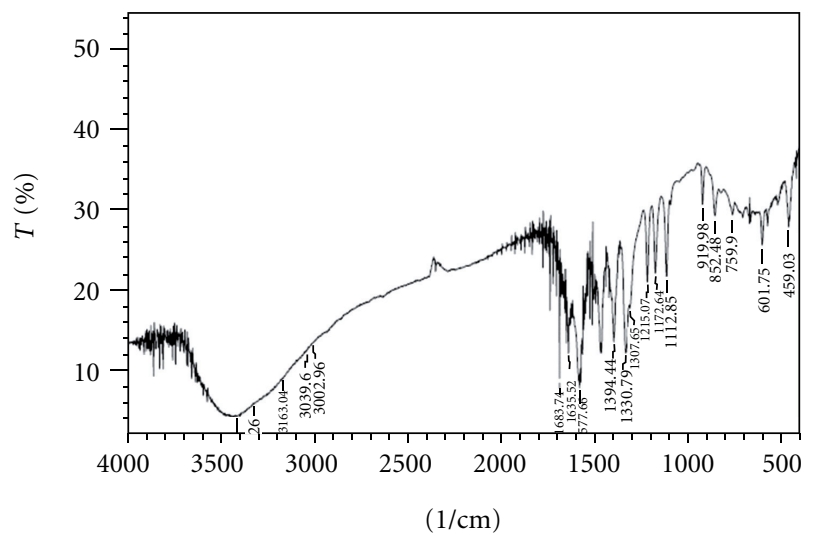

(b)

FIGURE 4: FTIR spectra of (a) 2,7-dichlorofluorescien hydrazide, (b) 2,7-dichlorofluorescien.

the solution was then heated on water bath until the foaming ceases in order to oxidize any elemental/ionic mercury (I) into mercuric (II) species. Then the solutions were cooled, and known aliquots were used for the analysis.

2.4.2. Water Samples. The water samples were collected using polyethylene containers from polluted lake (where painted clay idols were immersed after festival procession), unpolluted lake, and tap water supplied for drinking purpose. The water samples were filtered through Whatman filter paper to remove any suspended particulate matter. Then known aliquots of samples were used for mercury analysis.

2.4.3. Soil Samples. The soil samples were collected from agricultural field and soil sludge samples from the pond bed where the painted clay idols were immersed. Both the samples were collected from the site and stored in polyethylene bags. The soil samples were air dried, and the known weight (100 g) of the sample was placed in $250 \mathrm{~mL}$ beaker and extracted four times with $10 \mathrm{~mL}$ portions of concentrated hydrochloric acid each time. The combined extract was boiled for about $30 \mathrm{~min}$. Then the solution was cooled and diluted to $50 \mathrm{~mL}$ with distilled water. Then known aliquots of diluted samples were used for $\mathrm{Hg}^{2+}$ determination.

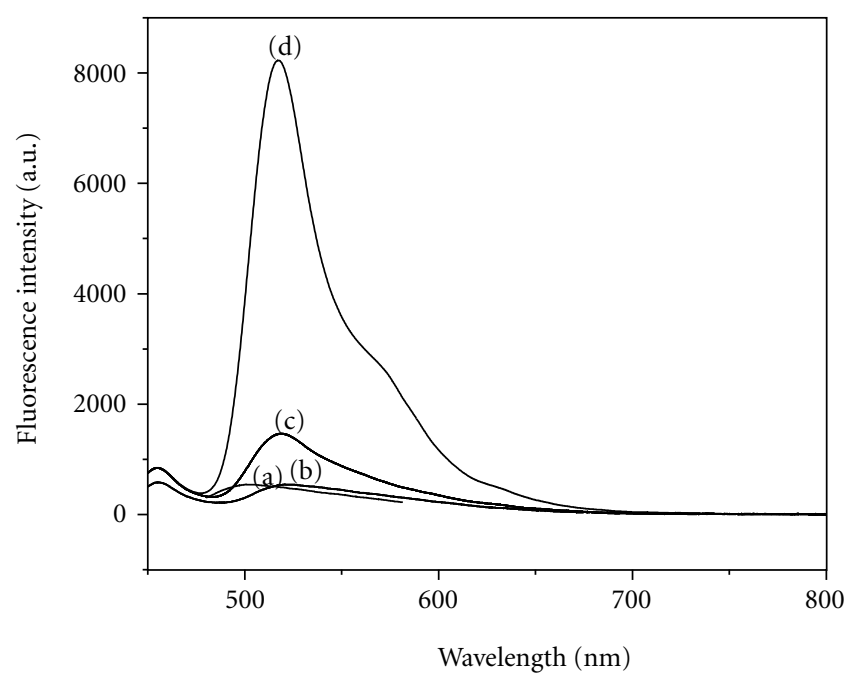

Figure 5: Fluorescence spectra of (a) Probe alone, (b) Probe $+\mathrm{Fe}^{2+}$, $\mathrm{Fe}^{3+}, \mathrm{Pb}^{2+}, \mathrm{Cd}^{2+}, \mathrm{Ni}^{2+}, \mathrm{Hg}^{+}, \mathrm{Mn}^{2+}, \mathrm{Zn}^{2+}(500 \mathrm{ng}),(\mathrm{c})$ Probe $+500 \mathrm{ng}$

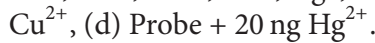

\section{Results and Discussion}

Xanthene-based derivatives are well-known chemosensors for the quantification of metal ions due to their specific quantitative reaction with metal ions through the spirolactam ring opening process [24]. The quantitative reactivity between these molecules and metal ions has lead to the development of a number of spectrophotometric- or fluorogenic-based protocols for the quantification of metal ions at trace level [24]. Mercuric (II) ion quantitatively reacts with colorless and nonfluorescent 2,7-dichlorofluorescein hydrazide to produce highly fluorescent green-colored 2,7-dichlorofluorescein in alkaline medium (Figure $1(\mathrm{~b}),\left(\mathrm{b}^{\prime}\right)$ ). The excitation and emission intensities of 2,7-dichlorofluorescein hydrazide are very low in the absence of mercury ions (Figure 1(a), $\left(a^{\prime}\right)$ ). The hydrozone group of the probe binds with $\mathrm{Hg}^{2+}$ ions leading to the formation of metal-ligand complex. Then the metal-ligand complex undergoes reductive hydrolytic cleavage resulting in the formation of 2,7-dichlorofluorescein, a green-colored fluorescent molecule (Scheme 2). This reaction scheme has been explored to develop a simple and selective spectrofluorimetric protocol for the quantification of mercury at ultratrace level. Similarly, the fluorescence spectra of the probe itself is weekly fluorescent due to its spiroform $(\lambda \mathrm{ex} / \mathrm{em}=502 / 520)$ in alkaline buffer, but upon the addition of mercury to this solution it results in the increase of fluorescence intensity (Figure 2). The color and fluorescence intensity change of 2,7-dichlorofluorescein hydrazide in presence of mercuric ion in alkaline medium $(\mathrm{pH}=12)$ at room temperature is specific for this particular ion. This property of this molecule, that is, transforming from colorless/nonfluorescent molecule into highly fluorescent deep green-colored species, could be used as a naked-eye detector for mercury in industrial atmospheres without any device being used in case of emergency industrial hazards. The simple naked-eye detector has been shown in Figure 3. 
TABLE 1: Interference study.

\begin{tabular}{lc}
\hline Interferent & $\begin{array}{c}\text { Concentration in } \\
\left(\mathrm{ngmL}^{-1}\right)\end{array}$ \\
\hline $\mathrm{F}^{-}, \mathrm{I}^{-}, \mathrm{Cl}^{-}, \mathrm{CH}_{3} \mathrm{COO}^{-}, \mathrm{CO}_{3}{ }^{2-}$ & 3000 \\
$\mathrm{SO}_{4}{ }^{2-}, \mathrm{S}^{2-}, \mathrm{PO}_{4}{ }^{3-}, \mathrm{HCO}_{3}{ }^{-}$ & 2500 \\
$\mathrm{NO}_{3}, \mathrm{NO}_{2}{ }^{-}$ & 2000 \\
$\mathrm{Fe}^{2+}, \mathrm{Fe}^{3+}, \mathrm{Ni}^{2+}, \mathrm{Zn}^{2+}, \mathrm{K}^{+}, \mathrm{Li}^{+}, \mathrm{Ca}^{2+}, \mathrm{Na}^{+}, \mathrm{Hg}^{+}, \mathrm{Pb}^{2+}$ & 2000 \\
$\mathrm{Cd}^{2+}, \mathrm{Mg}^{2+}, \mathrm{Co}^{2+}, \mathrm{Ni}^{2+}, \mathrm{Al}^{3+}, \mathrm{Cr}^{6+}, \mathrm{Mn}^{2+}$ & 500 \\
$\mathrm{Cu}^{2+}$ & 5 \\
\hline
\end{tabular}

3.1. Evidence for the Spirolactam Ring Opening Process. In order to prove that the reaction product obtained between the probe molecule and the metal ion is 2,7-dichorofluorescein, the reaction was carried out in bulk quantities. The product formed was isolated by extracting using ethyl acetate and purified by recrystallization. The recrystallized compound was characterized by FTIR study and elemental analysis.

3.1.1. FTIR Study. The obtained compound was subjected to FTIR study by making the pellet after mixing with IR grade $\mathrm{KBr}$ in $1: 100$ ratio. The IR spectrum of the isolated product (2,7-dichlorofluorescein) did not show any significant peaks for $\mathrm{N}-\mathrm{H}$ (primary amine) stretching at $3500 \mathrm{~cm}^{-1}$ (doublet) as well as $\mathrm{N}-\mathrm{C}=\mathrm{O}$ (amide) stretching at $1690 \mathrm{~cm}^{-1}$. However, characteristic significant peaks for 2,7-dichlorofluorescein have been observed. It has showed a strong stretching frequency at $3500 \mathrm{~cm}^{-1}$ due to $\mathrm{OH}$ moiety of $\mathrm{COOH}$ group. These studies have revealed that the compound formed is dichlorofluorescein (Figures 4(a) and 4(b)). These experimental observations have revealed that dichlorofluorescein hydrazide molecule catalyses in presence of mercury ions to generate a green-colored and highly fluorescent molecule that is dichlorofluorescein.

3.1.2. CHN Analysis. The CHN analysis of the synthesized 2,7-dichlorofluorescein and its authentic counterpart was carried out. The elemental analysis data has been found to be in good agreement with each other. The elemental analysis data for 2,7-dichlorofluorescein $\left[\mathrm{C}_{20} \mathrm{Cl}_{2} \mathrm{O}_{5} \mathrm{H}_{10}\right]$ both synthesized compound as well as authentic samples are given as below. Synthesized: C-59.894, H-2.463; Authentic: C59.884, H-2.493.

3.2. Optimization Study. The spectral properties of the 2,7dichlorofluorescein hydrazide usually depend on the $\mathrm{pH}$ as well as its concentration in solution phase because higher concentration of the dye may lead to molecular aggregation which in turn decreases the absorption. The presence of $\mathrm{Hg}^{2+}$ ion induces the ring opening of the probe molecule under selective $\mathrm{pH}$ condition. This $\mathrm{pH}$ selectivity can be used to prevent interference from the other metal ions by controlling the solution $\mathrm{pH}$. The reaction variables have been carried out to get the maximum sample absorbance with the minimum blank value.
3.2.1. Effect of $p H$. The reaction between 2,7-dichlorofluorescein hydrazide and mercury proceeds only in alkaline condition; hence, the effect of medium $\mathrm{pH}$ was studied in the range of 7-12. The fluorescence intensity values of 2,7dichlorofluorescein gradually increased with the increase in $\mathrm{pH}$, and the maximum fluorescence emission was observed between $\mathrm{pH} 9$ and 12, and hence an optimum $\mathrm{pH}$ value was maintained at 12 by the addition of $1 \mathrm{~mL}$ of buffer $(\mathrm{pH}$ $=12$ ) in all further studies. Therefore, initial studies were carried out using $10 \mathrm{ngmL}^{-1}$ of mercury (II) in the presence of $0.5 \mathrm{~mL}$ of $10 \mathrm{mM}$ 2,7-dichlorofluorescein hydrazide in $10 \mathrm{~mL}$ volumetric flask. The solutions were allowed for two minutes for the reaction completion, and the fluorescence values were measured at $520 \mathrm{~nm}$.

\subsubsection{Effect of 2,7-Dichlorofluorescien Hydrazide con-} centration. The optimum concentration of the 2,7dichlorofluorescein hydrazide required to react with $10 \mathrm{ngmL}^{-1}$ mercury ion was examined by varying its concentration between 5 and $30 \mathrm{mM}$. The sample gave maximum fluorescence intensity beyond $20 \mathrm{mM}$ concentration which was achieved by the addition of $2 \mathrm{~mL}$ of $10 \mathrm{mM} \mathrm{2,7-dicholorofluorescein} \mathrm{in} 10 \mathrm{~mL}$ volume.

3.3. Interference Study. In order to apply the proposed method to quantify mercury (II) ion at trace level from natural and environmental samples, the interference effect of common cations and anions that normally exist in natural water samples was studied. The interfering species were added in their respective salt forms, and its impact on the signaling behavior of 2,7-dichlorofluorescien hydrazide with $\mathrm{Hg}^{2+}$ ion was studied. The spectral interference of several metal ions with 2,7-dichlorofluorescien hydrazide is insignificant when compared to mercury (II) including $\mathrm{Cu}^{2+}$ at $\mathrm{pH} 12$ (Figure 5). Cupric ion induces fluorescence below $\mathrm{pH}$ 8; hence, the interference of copper can be overcome by controlling the $\mathrm{pH}$. The control of $\mathrm{pH}$ can be easily achieved, thereby the selectivity towards mercury becomes more facile in aqueous condition. Hence, the proposed method showed high selectivity towards $\mathrm{Hg}^{2+}$ ions in the $\mathrm{pH}$ range of 9-12. No other metal ions including several anions induce the spirolactam ring opening of 2,7-dichlorofluorescien hydrazide to give 2,7-dichlorofluorescien at this $\mathrm{pH}$. The tolerance limits for various metal ions and anions have been studied (Table $1)$.

3.4. Application Study. The proposed method has been validated by determining trace level mercury concentrations from a variety of natural samples like water, soil and industrial effluents. The water and soil, sludge samples were collected from the lake polluted due to the dumping of the clay idols after festival procession. These clay idols slowly dissolve in water releasing pigments containing toxic metal ions like mercury, lead, arsenic, and so forth into water as well as soil bed of the lake. The mercury content in these water and soil sludge samples of the lake was analyzed by the procedure described elsewhere. Recovery studies were also carried out by spiking the samples with known 


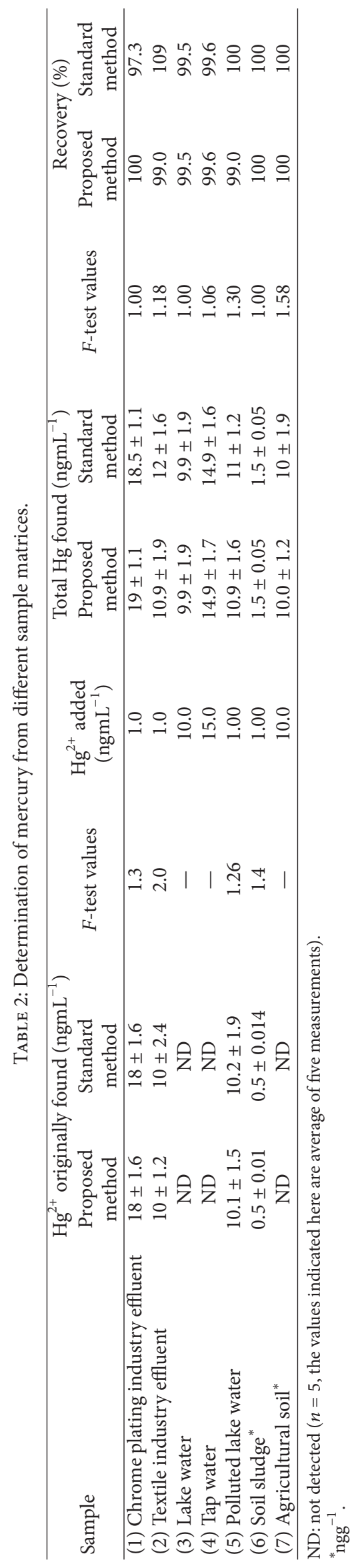


<smiles>NNC(=O)c1ccccc1C1(NN)c2cc(Cl)c(O)cc2Oc2cc(O)c(Cl)cc21</smiles>

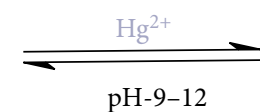

2,7-Dichlorofluorescein hydrazide colorless, nonfluorescent
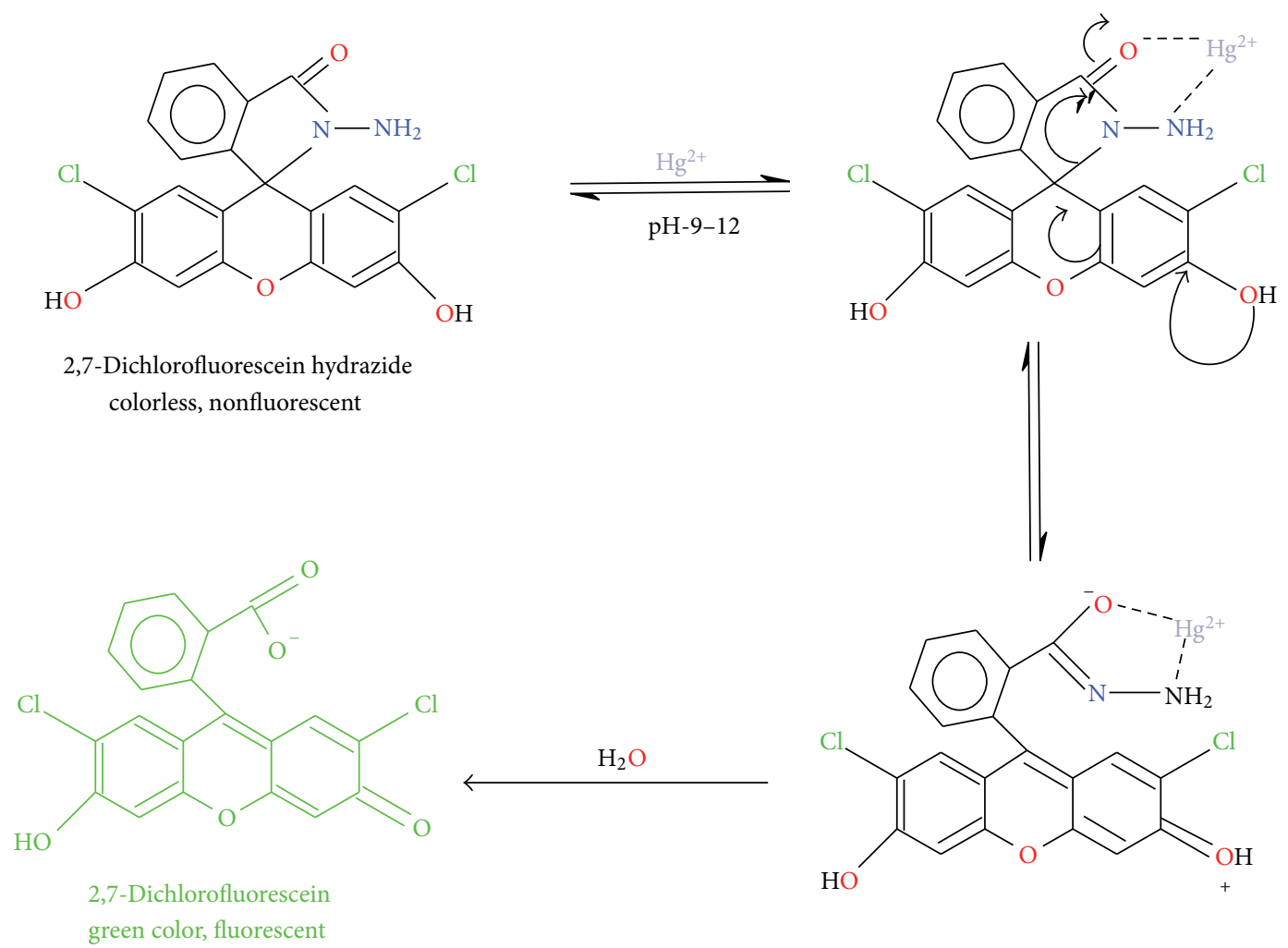<smiles></smiles>

Scheme 2: Schematic representation of mechanistic pathway of 2,7-dichlorofluorescein hydrazide and its reaction with mercury ions.

concentrations of mercury to these samples, and the results have been compared with that of standard method [28]. The agricultural soil was collected from the irrigation land where several kinds of fertilizers were applied to improve the yield. The mercury was not detected in these samples; however, recovery studies were carried out by spiking this sample. The industrial effluents were collected from local area pollution control board where the pretreated industrial effluents were examined to check the quality of treated effluents for metal ion removal. These samples were used to determine the mercury levels by the proposed method, and the results obtained have been compared with the standard dithizone method. The results obtained by the proposed method were in good agreement with the standard method (Table 2).

\section{Conclusion}

A simple and sensitive protocol has been developed for mercury quantification using 2,7-dichlorofluorescein hydrazide as a fluorescent probe based on the spirolactam ring opening of the molecule by the metal ion in alkaline medium at nanogram level. The proposed method can be used as a naked-eye sensor in industrial atmospheres as a prewarning signal whenever the high levels of mercury have been discharged in industrial effluents. The molecule is highly selective to divalent mercury, and most of the common metal ions present in water do not interfere significantly including copper which can be prevented by $\mathrm{pH}$ control. The developed method has been successfully applied to determine trace level mercury from industrial effluents as well as water samples. The results obtained by the proposed method have been compared with standard method, and the results are in good agreement. The precision of the method was evaluated by calculating the F-test values. The proposed chemosensor for mercury quantification is simple, fast, highly sensitive, and selective which can be used as an alternative protocol to the existing methods in industrial establishments where mercury-based industrial effluents have been processed.

\section{Acknowledgment}

The authors acknowledge the financial support and award of the fellowship to K. Sureshkumar by the University Grants Commission (UGC), New Delhi, India.

\section{References}

[1] "Regulatory impact analysis of the clean air: mercury rule," US EPA, EPA-452/R-05-003, 2005.

[2] J. R. Miller, J. Rowland, P. J. Lechler, M. Desilets, and L. C. Hsu, "Dispersal of mercury-contaminated sediments by geomorphic processes, Sixmile Canyon, Nevada, USA: implications to site characterization and remediation of fluvial environments," Water, Air, and Soil Pollution, vol. 86, no. 1-4, pp. 373-388, 1996.

[3] Environmental Chemistry and Toxicology of Mercury, John Wiley \& Sons, New York, NY, USA, 1st edition, 2012. 
[4] A. Renzoni, F. Zino, and E. Franchi, "Mercury levels along the food chain and risk for exposed populations," Environmental Research, vol. 77, no. 2, pp. 68-72, 1998.

[5] G. Moro, M. Lasagni, N. Rigamonti, U. Cosentino, and D. Pitea, "Critical review of the receptor model based on target transformation factor analysis," Chemosphere, vol. 35, no. 8, pp. 1847-1865, 1997.

[6] D. W. Boening, "Ecological effects, transport, and fate of mercury: a general review," Chemosphere, vol. 40, no. 12, pp. 1335-1351, 2000.

[7] L. Balint, I. Vedrina-Drajevic, B. Sebecic, and J. MomirovicCuljat, "Spectrofluorometric method for determination of the total mercury in natural water," Zeitschrift für Lebensmitteluntersuchung und -Forschung, vol. 198, pp. 29-32, 1994.

[8] P. D. Selid, H. Xu, E. M. Collins, M. S. Face-Collins, and J. $\mathrm{X}$. Zhao, "Sensing mercury for biomedical and environmental monitoring," Sensors, vol. 9, no. 7, pp. 5446-5459, 2009.

[9] F. Sancenón, R. Martínez-Máñez, and J. Soto, “1,3,5Triarylpent-2-en-1,5-diones for the colorimetric sensing of the mercuric cation," Chemical Communications, vol. 21, no. 21, pp. 2262-2263, 2001.

[10] T. Gunnlaugsson, J. P. Leonard, and N. S. Murray, "Highly selective colorimetric naked-eye $\mathrm{Cu}(\mathrm{II})$ detection using an azobenzene chemosensor," Organic Letters, vol. 6, no. 10, pp. 1557-1560, 2004.

[11] N. Kaur and S. Kumar, "A diamide-diamine based $\mathrm{Cu}^{2+}$ chromogenic sensor for highly selective visual and spectrophotometric detection," Tetrahedron Letters, vol. 47, no. 25, pp. 4109-4112, 2006.

[12] K. N. Kim, M. G. Choi, J. H. Noh, S. Ahn, and S. K. Chang, "Rhodamine B hydrazide revisited: chemodosimetric $\mathrm{Hg}^{2+}$ selective signaling behavior in aqueous environments," Bulletin of the Korean Chemical Society, vol. 29, no. 3, pp. 571-574, 2008.

[13] S. Yoon, A. E. Albers, A. P. Wong, and C. J. Chang, "Screening mercury levels in fish with a selective fluorescent chemosensor," Journal of the American Chemical Society, vol. 127, no. 46, pp. 16030-16031, 2005.

[14] S. H. Kim, J. S. Kim, S. M. Park, and S. K. Chang, " $\mathrm{Hg}^{2+}$-selective OFF-ON and $\mathrm{Cu}^{2+}$-selective ON-OFF type fluoroionophore based upon cyclam," Organic Letters, vol. 8, no. 3, pp. 371-374, 2006.

[15] L. P. Singh and J. M. Bhatnagar, "Copper(II) selective electrochemical sensor based on Schiff Base complexes," Talanta, vol. 64, no. 2, pp. 313-319, 2004.

[16] Z. Liu, S. Huan, J. Jiang, G. Shen, and R. Yu, "Molecularly imprinted $\mathrm{TiO}_{2}$ thin film using stable ground-state complex as template as applied to selective electrochemical determination of mercury," Talanta, vol. 68, no. 4, pp. 1120-1125, 2006.

[17] A. P. De Silva, H. Q. N. Gunaratne, T. Gunnlaugsson et al., "Signaling recognition events with fluorescent sensors and switches," Chemical Reviews, vol. 97, no. 5, pp. 1515-1566, 1997.

[18] B. Valeur and I. Leary, "Design principles of fluorescent molecular sensors for cation recognition," Coordination Chemistry Reviews, vol. 205, no. 1, pp. 3-40, 2000.

[19] I. B. Kim, B. Ergodan, J. N. Wilson, and U. H. F. Bunz, "Sugarpoly (para ethynylene) conjugates as sensory materials: efficient quenching by $\mathrm{Hg}^{2+}$ and $\mathrm{Pb}^{2+}$ ions," Chemistry, vol. 10, no. 24, pp. 6247-6254, 2004.

[20] A. Cabellero, V. M. Lloveras, I. Ratera et al., "Dipyrrolyldiketonedifluoroboron complexes: novel anion sensors with $\mathrm{C}-\mathrm{H}$. · $\mathrm{X}^{-}$interactions," Chemistry, vol. 11, no. 19, pp. 5661-5666, 2005.
[21] J. Wang and X. Qian, "Two regioisomeric and exclusively selective $\mathrm{Hg}$ (II) sensor molecules composed of a naphthalimide fluorophore and an o-phenylenediamine derived triamide receptor," Chemical Communications, vol. 1, pp. 109-111, 2006.

[22] C. Xiniqi and M. Huimini, "A selective fluorescence-on reaction of spiro form fluorescein hydrazide with $\mathrm{Cu}(\mathrm{II})$," Analytica Chimica Acta, vol. 575, no. 2, pp. 217-222, 2006.

[23] C. Xiaoqiang, P. Tuhin, W. Fang, S. K. Jong, and Y. Juyoung, "Fluorescent chemosensors based on spiroring-opening of xanthenes and related derivatives," Chemical Reviews, vol. 112, no. 3, pp. 1910-1956, 2012.

[24] H. N. Kim, M. H. Lee, H. J. Kim, J. S. Kim, and J. Yoon, "A new trend in rhodamine-based chemosensors: application of spirolactam ring-opening to sensing ions," Chemical Society Reviews, vol. 37, no. 8, pp. 1465-1472, 2008.

[25] V. Dujols, F. Ford, and A. W. Czarnik, "A long-wavelength fluorescent chemodosimeter selective for $\mathrm{Cu}(\mathrm{II})$ ion in water," Journal of the American Chemical Society, vol. 119, no. 31, pp. 7386-7387, 1997.

[26] M. Pandurangappa and K. S. Kumar, "Micellar mediated trace level mercury quantification through the rhodamine B hydrazide spirolactam ring opening process," Analytical Methods, vol. 3, no. 3, pp. 715-723, 2011.

[27] W. Jia-sheng, K. H. Jung, L. M. Hee, Y. J. Hee, L. J. Hae, and K. Jong, "Anion-induced ring-opening of fluorescein spirolactam: fluorescent OFF-ON," Tetrahedron Letters, vol. 48, no. 18, pp. 3159-3162, 2007.

[28] American Water Works Association and Water Pollution Control Federation, Standard Methods for the Examination of Water and Wastewater, American Public Health Association, Washington, DC, USA, 18th edition, 1992. 

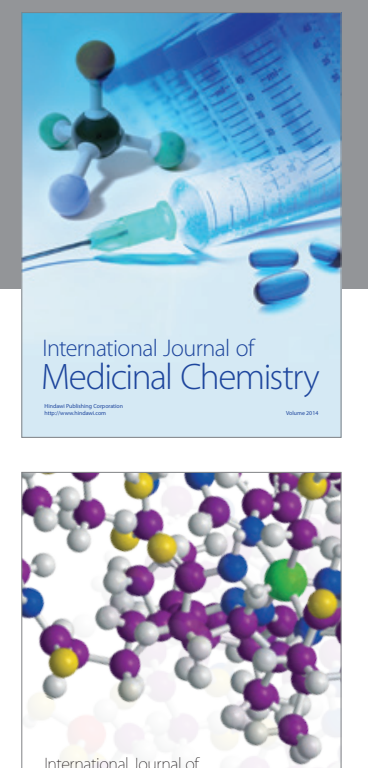

\section{Carbohydrate} Chemistry

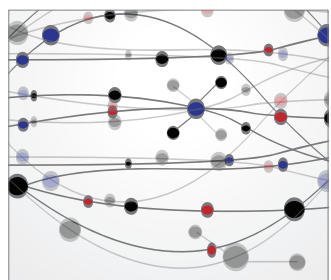

The Scientific World Journal
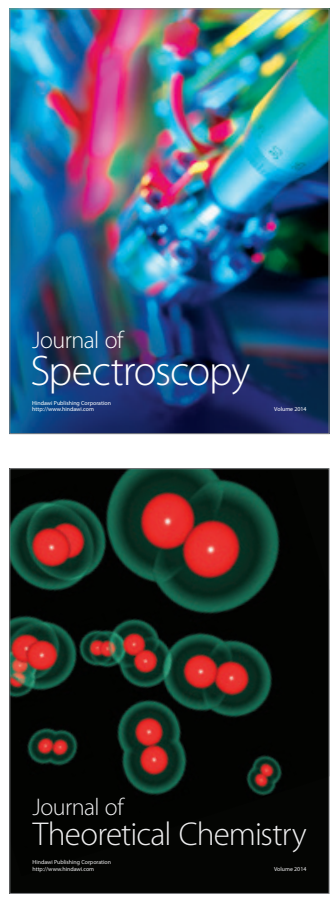
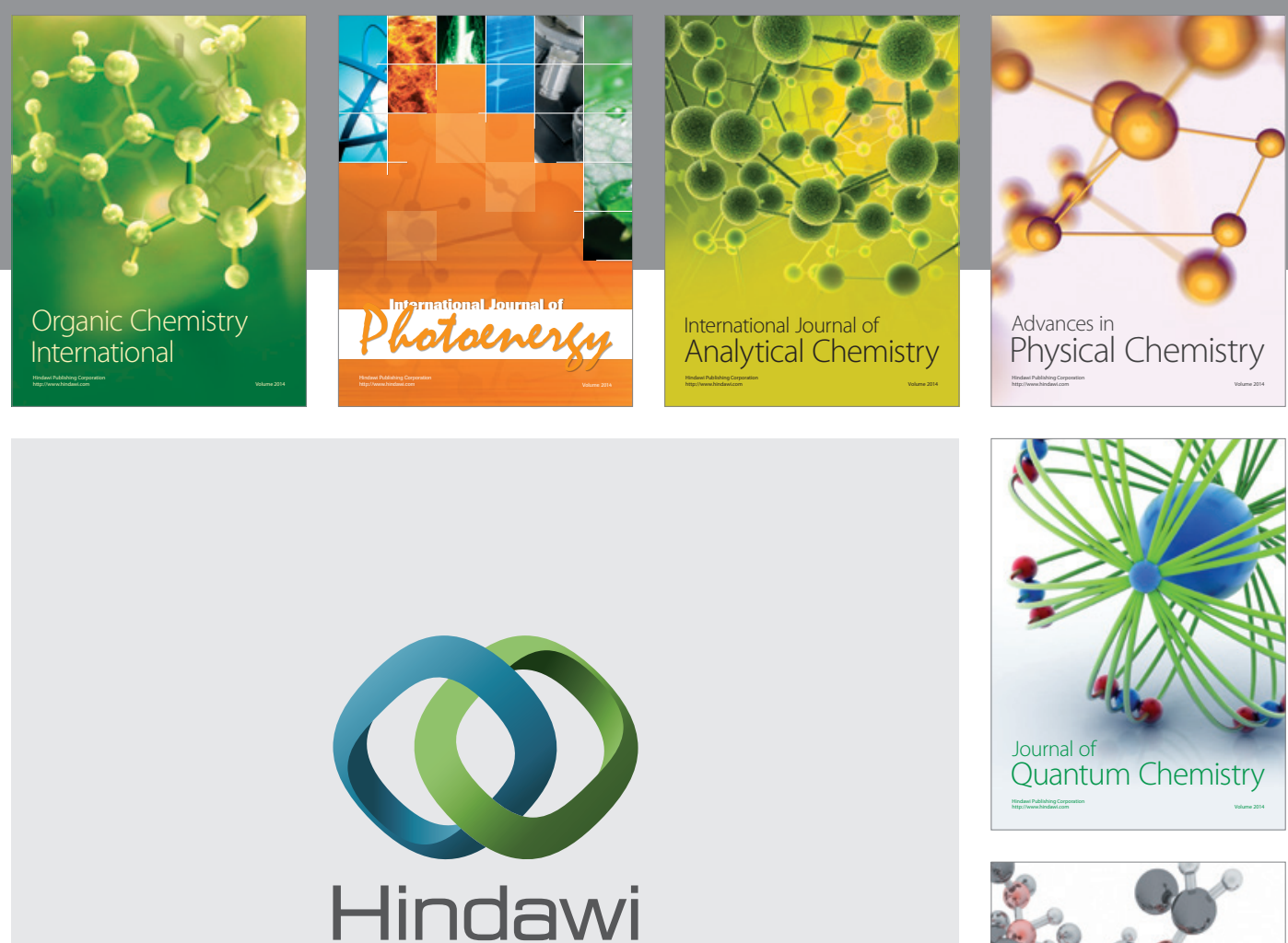

Submit your manuscripts at

http://www.hindawi.com

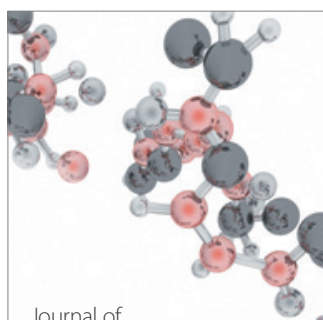

Analytical Methods

in Chemistry

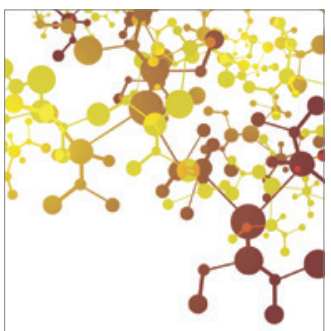

Journal of

Applied Chemistry

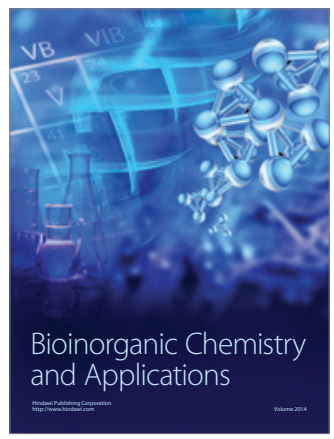

Inorganic Chemistry
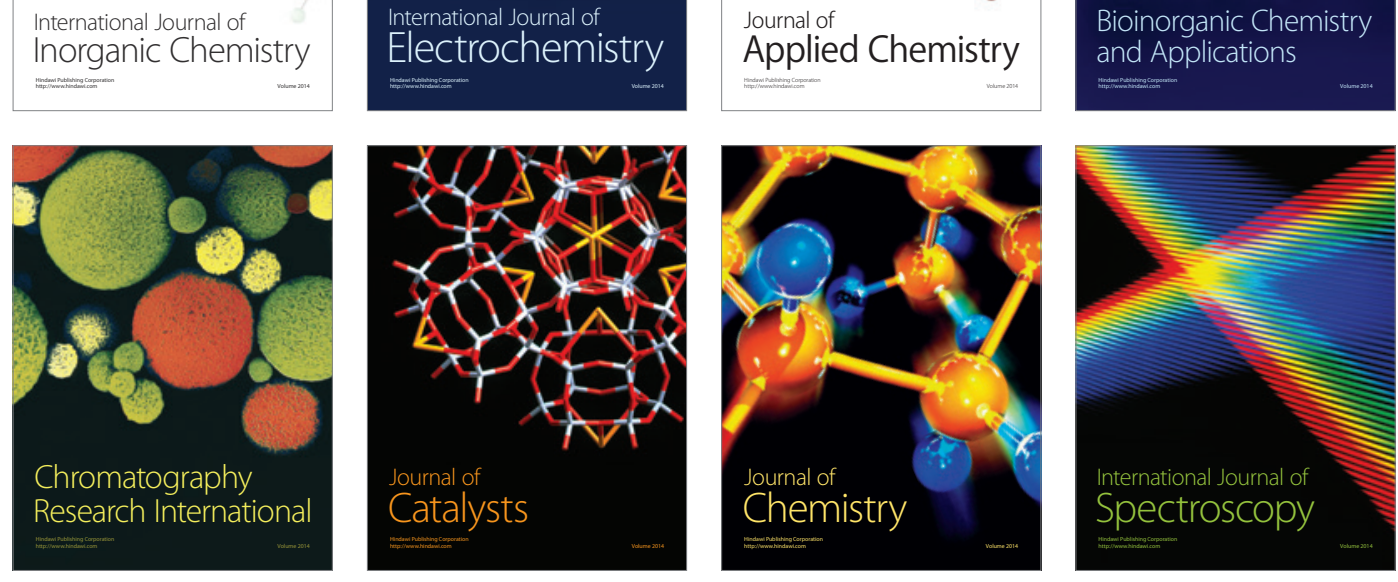